\title{
The effects of early malnutrition on one-way and two-way avoidance behavior*
}

\author{
CHARLES J. MORRIS \\ Denison University, Granville, Ohio 43023
}

\begin{abstract}
The effects of early malnutrition on performance on a one-way and a two-way avoidance task were investigated. Animals malnourished early in life were found to perform better than normal animals on the two-way task, but no significant differences were found between groups on the one-way task. The results were interpreted as indicating that early malnutrition produces a deficit in the ability to inhibit irrelevant or nonreinforced responses.
\end{abstract}

Although most investigations of the effects of early malnutrition on later performance have been concerned with what might be called "general learning ability," a close examination of the literature in this area suggests that many of the behavioral deficits produced by early malnutrition might be interpreted in terms of an inability to inhibit irrelevant or nonreinforced responses. For example, increased errors on a Hebb Williams maze (Zimmermann \& Wells, 1971), poor discrimination performance (Barnes et al, 1966), and slower extinction rates (Barnes et al, 1968) have been reported for animals suffering from early malnutrition. Each of these effects could be interpreted as a deficit in the ability to inhibit nonreinforced responses. Even the finding that malnourished animals are more emotional than normals (Levitsky \& Barnes, 1970) might conceivably be due to a failure to habituate, i.e., inhibit responses, to novel stimulation. Tasks which do not involve response inhibition, on theother hand, such as classical conditioning, do not differentiate malnourished and normal animals (Barnes et al, 1968).

The purpose of the present experiment was to test a response-inhibition interpretation of the effects of early malnutrition on behavior. Specifically, normal and malnourished animals were compared on a one-way and a two-way avoidance task. These tasks were selected because, according to the response-inhibition hypothesis, deficits in inhibition should have no effect on one-way performance but should actually improve two-way performance. This latter effect is predicted because of the inherent passive avoidance contingency in a two-way avoidance task (see Douglas, 1967). Note also that the predicted enhancement of performance runs counter to interpretations of malnutrition based upon the concept of general learning ability. Confirmation of the response-inhibition hypothesis in this case, moreover, would provide evidence against explanations of the effects of early malnutrition in terms of sensory and/or

*Requests for reprints should be addressed to the author Department of Psychology, Denison University, Granville, Ohio 43023 . motor deficits, factors which have not been controlled adequately in previous investigations.

\section{METHOD}

\section{Subjects}

Twenty-four Carworth CFE albino rats (Rattus norvegicus), 12 males and 12 females, served as $S s$ in the experiment. One-half of the animals (normal group) were selected at random from three litters of eight pups each, who had been suckled from mothers maintained on a $21 \%$ protein diet prior to and following parturition. The remaining one-half of the animals (deficient group) were randomly selected from three litters of eight pups each, who had been suckled from mothers fed an $8 \%$ protein diet for 12 days following parturition. Prior to and beginning on the 13 th day following delivery, the mothers were fed a $21 \%$ protein diet. All pups were weaned at 21 days of age, placed in individual cages, and maintained on the $21 \%$ protein diet for the remainder of the experiment. Avoidance testing began when the animals reached 90 days of age. 1

\section{Apparatus}

The animals were tested in a shuttlebox (Lehigh Valley Electronics, Model 146-04) located in a quiet darkened room. A sliding door separated the two sides of the shuttlebox, one side of which was black and the other white. Illumination was provided by a small light at each end of the chamber.

A $2.5-\mathrm{kHz}$ tone coupled with the opening of the sliding door served as a conditioned stimulus (CS), and the unconditioned stimulus (US) was a 2-mA pulsed shock (200-msec shock every $2 \mathrm{sec}$ ) delivered through the grid floor of the shuttlebox. Except for the opening of the sliding door, which was done manually, all experimental operations and data recording were controlled by electromechanical equipment located in an adjacent room.

\section{Procedure}

Each group of animals was divided into two groups of six animals each (three males, three females). Thus, four groups of six animals each were formed. One normal and one deficient group were then tested on the one-way avoidance task, and the remaining groups were tested on the two-way task.

One-Way Avoidance. The one-way task involved 20 trials per day for 3 successive days. On a given trial, the animal was placed by hand into the black side of the shuttlebox, the CS was presented, and, if the animal failed to jump to the other side within $10 \mathrm{sec}$, the shock was delivered until an escape response was made. At the end of each trial, the door was closed and the animal was placed back into the original side. A 1-min interval separated the end of one trial and the onset of the next. 


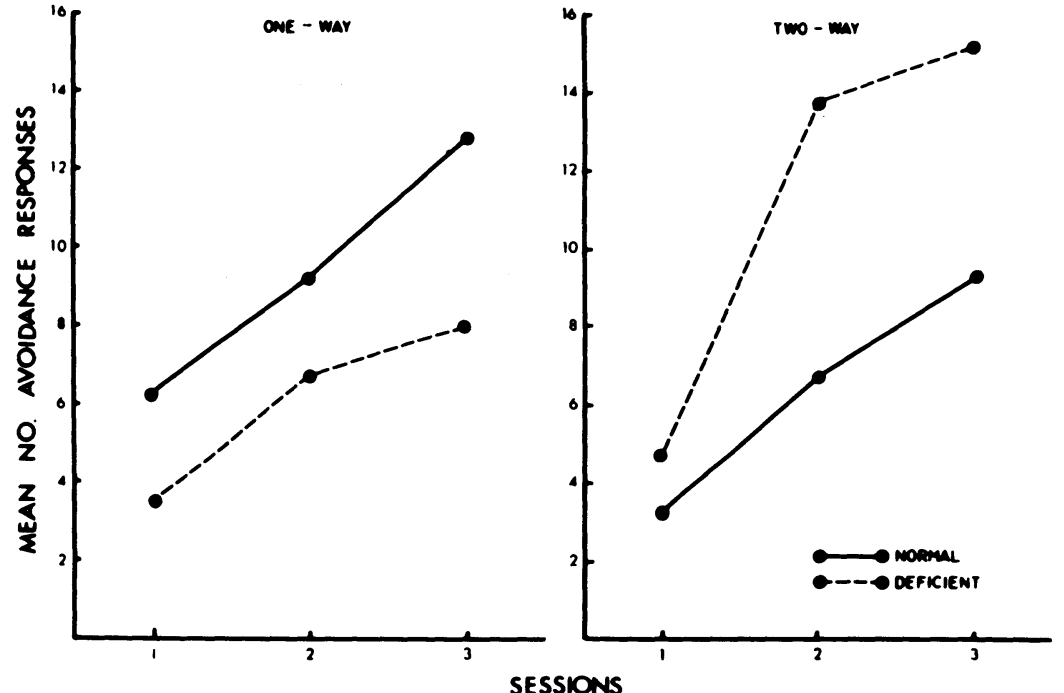

Fig. 1. Mean number of avoidance responses for the normal and deficient animals on the one-way and two-way avoidance tasks.
Two-Way Avoidance. The above procedure was followed for the two-way task except that the animal was required to shuttle back and forth between the black and white sides of the shuttlebox from one trial to the next. In other words, on the first trial of each session, the animal was required to avoid or escape from the black side by jumping into the white side; on the next trial, it was required to avoid or escape by jumping from the white side into the black side, etc. Note the passive avoidance contingency built into the two-way task: On each successive trial, the animal must return to the side of the shuttlebox in which it had been shocked on the previous trial. The one-way task, on the other hand, involved no such contingency.

\section{RESULTS}

The average number of avoidance responses made by the normal and deficient animals on the one-way and two-way avoidance tasks is shown in Fig. 1. Separate analyses of variance on these data revealed, in addition to the obvious sessions effect on both tasks, a significant difference between groups on the two-way task $(\mathrm{F}=$ $9.72, \mathrm{df}=1 / 10, \mathrm{p}<.025)$; however, the main effect of groups on the one-way task failed to reach statistical reliability $(\mathrm{F}=2.12, \mathrm{df}=1 / 10, \mathrm{p}>.10)$. Observation of the deficient animals on the one-way task suggested that their slightly poorer performance was due to the failure of some of the animals to adapt to being handled during the intertrial interval.

A more refined analysis of the two-way avoidance data revealed an interesting difference between the normal and deficient animals as a functionof whether they were responding to or away from the side of the shuttlebox on which they were initially shocked at the onset of each session. Examination of Fig. 2 shows that the normal animals performed very poorly when they were required to return to the initial starting side of the shuttlebox. The deficient animals, on the other hand, performed equally well going to or away from the side on which they were first shocked. These directional effects on the two-way task proved to be highly significant, as indicated by both the main effect of directions $(F=10.77$, df $=1 / 50, p<.005)$ and the Groups by Directions interaction $(F=17.98, d f=1 / 50$, $\mathrm{p}<.001$ ). It should be noted that all animals received rather lengthy shocks on the first trial of avoidance testing. Apparently, this initial experience with shock at the start of escape/avoidance training was sufficient to establish a strong passive avoidance response in the normal animals. Consistent with the view that early protein deficiency produces an inability to inhibit responses, however, the deficient animals failed to develop a strong passive avoidance tendency as a result of the initial shock experience, and thus performed better than the normal animals.

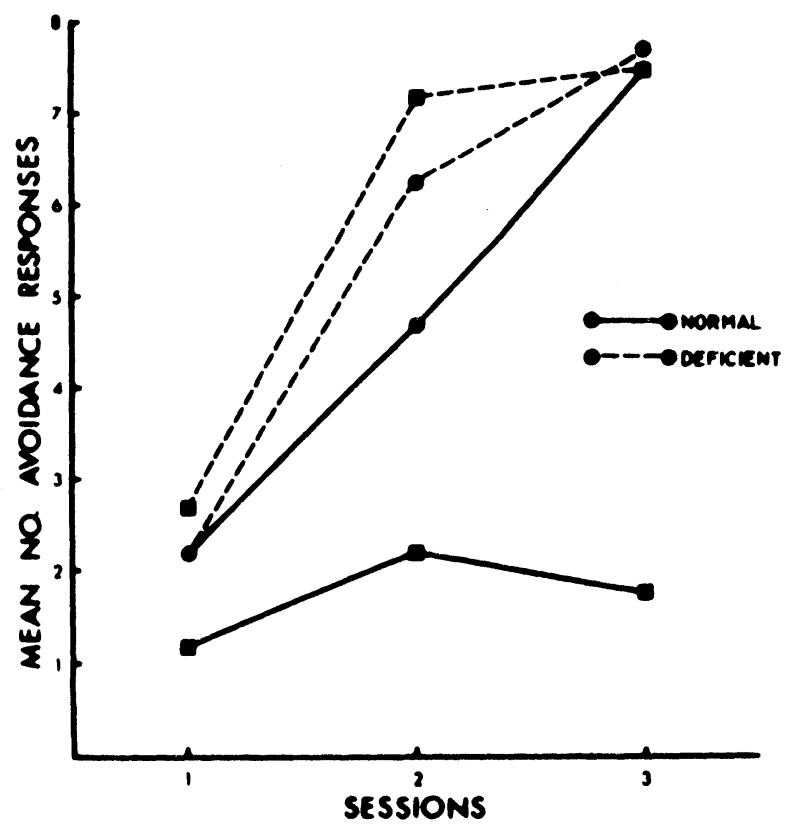

Fig. 2. Mean number of avoidance responses for the normal and deficient animals going toward (squares) or away from (circles) the side of the shuttlebox on which the animals were initially shocked at the onset of each session (two-way task). 
Finally, an analysis of avoidance latencies to and away from the side on which shock was first received tended to support a response inhibition interpretation of the data. For the normal group, latencies were no longer when the animals successfully avoided the shock by jumping to the initial side compared to when they jumped away from that side, thus suggesting a stronger tendency to avoid the side of the shuttlebox on which shocks were initially received. However, this effect was only marginally significant $(\mathrm{t}=2.34, \mathrm{df}=5, \mathrm{p}<.10)$. No directional effects in avoidance latencies were found for the deficient animals $(\mathrm{t}=1.06, \mathrm{df}=5, \mathrm{n} . \mathrm{s}$.).

\section{DISCUSSION}

The clear-cut results of the present study provide strong support for a response-inhibition interpretation of the effects of early malnutrition on behavior. Moreover, the fact that the deficient animals actually performed significantly better than the normals on the two-way avoidance task-as would be expected if they suffered from an inability to withhold responses-indicates clearly that explanations of the effects of early malnutrition in terms of deficits in general learning ability or sensory-motor impairment are inadequate.

However, the results are not in accord with those reported by Levitsky and Barnes (1970), who found that previously malnourished animals remained longer on a platform than did controls after they had been shocked for stepping off the platform onto a grid floor. The issue is complicated further by the results of a recent study (Smart \& Dobbing, 1972), in which no differences in passive avoidance were found between underfed and normal animals. Although large procedural differences exist between the present and earlier studies (e.g., strain differences, testing apparatus, and age at testing), it does not appear possible to account for these varied results at the present time.
The widespread effects of early malnutrition on the developing brain (Altman, Das, \& Sudershan, 1970; Winick, 1970) may result in the disruption of several behavioral processes which, in turn, interact in unknown ways with the particulars of the experimental situation in which the animal is placed. Teasing out these various relationships appears to be the challenge for future experimentation in this area.

\section{REFERENCES}

Altman, J., Das, G. D., \& Sudershan, K. The influence of nutrition on neural and behavioral development. I. Critical review of some data on the growth of the body and the brain following dietary deprivation during gestationand lactating. Developmental Psy chobiology, 1970, 3, 281-301.

Barnes, R., Cunnold, S., Zimmermann, R., Simmons, H., MacCleod, R., \& Krook, W. Influence of nutrition deprivations in early life on learning behavior of rats as measured by performance in a water maze. Journal of Nutrition, 1966, 89, 399-410.

Barnes, R., Moore, A., Reid, I., \& Pond, W. Effects of food deprivation on behavior patterns. In $\mathbf{N}$. Scrimshaw and $J$. Gorden (Eds.), Malnutrition, learning and behavior. Cambridge: M.I.T. Press, 1968. Pp. 203-217.

Douglas, R. J. The hippocampus and behavior. Psychological Bulletin, 1967, 67, 416-442.

Levitsky, D., \& Barnes, R. Effect of early malnutrition on the reaction of adult rats to aversive stimuli. Nature, London, $1970,225,468-469$.

Smart, J. L, \& Dobbing, J. Vulnerability of developing brain: IV. Passive avoidance behavior in young rats following maternal undernutrition. Developmental Psychobiology, 1972, 5, 129-136.

Winick, $M$. Nutrition and nerve cell growth. Federation Proceedings, 1970, 29, 1510-1515.

Zimmermann, R. R., \& Wells, A. M. Performance of malnourished rats on the Hebb-Williams closed-field maze learning task. Perceptual \& Motor Skills, 1971, 33, 1043-1050.

\section{NOTE}

1. The protein manipulations used in the present study had the effect of reducing the adult weights of the deficient animals by about $25 \%$ compared to the normals.

(Received for publication November 15, 1973; revision received February $7,1974$. 